\title{
Cancer and Schizophrenia
}

\section{Opinion}

Are schizophrenics having more or less cancer? This is a controversial topic, which raised a lot of debates. The website www. news-medical.net/.../people-with-schizophrenia-are-more-likely-todevelop-cancer ${ }^{1}$ claims that schizo-phrenics are 2.6 times more likely to develop cancer.

However, studies in Finland of Lichtermann and collaborators showed that while the breast cancer in higher in schizophrenics, the lung cancer seems to be lower despite of smoking. Nobody can explain why the results are so controversial and what we should believe. We will try to explain why.

Hans Selye $^{2}$ who devoted 40years of his life to study stress, explained that the stress reaction of every normal individual has three stages: alarms signal that stressor is present, mobilization reaction for response to the stressor, and relaxation (going back to normal state when the stressor is not present any more). The relaxation time takes three to four days. ${ }^{3}$

According to Hans Selye, the stress reaction of schizophrenics has only two stages: alarms signal that stressor is present and mobilization reaction for response to the stressor. There is no relaxation or going back to norm, which means that schizophrenics are in a state of permanent stress.

Every new stressor causes mobilization reaction, which is piled on top of the mobilization reaction for response to the previous stressor. The author of this article thinks that this explains the fact that schizophrenics live in illusory world. They imagine things the way they want them to be to avoid more stress.

The author explained in previous articles how stress causes cancer. ${ }^{4,5}$ If schizophrenics have a broken mechanism of stress response, which makes them to be in a state of permanent stress, it is natural to expect them to have higher rate of cancer. Also stress weakens the immune system.

The broken mechanism of stress response seems to be at the basis of other strange characteristics of schizophrenics. It was found ${ }^{6}$ that schizophrenics couldn't follow with their eyes the movement of a pendulum as normal people do. The movement of their eyes is chaotic. What this has to do with their broken stress mechanism?

Stress creates delays because the body needs to stop what it was doing and mobilize for response to the stressor. These delays time shift the biorhythms destroying their time organization; until a point is reached at which nothing is left from the organization, which will be chaotic state.

I want to share with you my own observation of chaotic behavior of the nonlinear electromagnetic field (NEMF) of a schizophrenic young woman. When I tried to measure the spinning energy centers (alternating vortices and anti-vortices) of her NEMF with my sensitive patented equipment, the energy centers exhibited chaotic behavior.?
Volume II Issue 4 - 2018

\author{
Maria Kuman \\ Holistic Research Institute, USA
}

Correspondence: Maria Kuman, Holistic Research Institute, I 4 I 4 Barcena Dr., Knoxville, TN 37923, USA, Email holisticare@mariakuman.com,www.mariakuman.com

Received: June 04, 2018 | Published: July 19, 2018

The energy of the alternating vortices and anti-vortices of the NEMF of this schizophrenic woman was changing in an unpredictable way in a split second. I have measured the energy centers of normal individuals for years. The energy was stable and could be measured and re-measured again and again and it was always the same.

For the first time, I had observed chaos like this, and this was when the schizophrenic individual was claiming that demons are trying to possess her. The explanation of the author is: probably the broken stress response of schizophrenics lead to excessive stress, which has totally disordered their NEMF and made it chaotic.

Normally, schizophrenic individuals are sexually over-active. This can be observed in their behavior and the measured energy of their sexual energy center (of their NEMF) is higher than normal. This could explain the higher accident of breast cancer among schizophrenics because the breast hormones are related to the sexual hormones.

\section{Acknowledgements}

None.

\section{Conflict of interest}

The author declares no conflict of interest.

\section{References}

1. https://www.news-medical.net

2. Selye, Hans. The Stress of Life. New York, USA; 1956.

3. Stress in Health and Disease. In: Hans Selye, editor. 1976.

4. Waldman. Actualnie Problemi Stressa (Actual Problems of Stress). Russia: Kishinev; 1976.

5. Kuman M. Cancer is a Lost Control over Cellular Growth Caused by Stress. Advances in Complimentary and Alternative Medicine. 2018;4(1):1-2.

6. Kuman M. Advances in Complimentary and Alternative Medicine. 2018:2(4).

7. Gleick J. Chaos. New Zealand: Penguin Books; 1988. 